MEDICAL GENETICS IN PRACTICE

\title{
Referral for cancer genetics consultation: a review and compilation of risk assessment criteria
}

\author{
H Hampel, K Sweet, J A Westman, K Offit, C Eng
}

J Med Genet 2004;41:81-91. doi: 10.1136/jmg.2003.010918

See end of article for authors' affiliations

.....................

Correspondence to: Ms Heather Hampel, The Ohio State University, 8th Floor Tower, 2050 Kenny $\mathrm{Rd}$, Columbus, $\mathrm{OH} 43221$, USA;

hampel-2@medctr.osu.edu

Received 2 June 2003

Accepted

29 September 2003
Background: There have been many papers on the diagnostic criteria for specific hereditary cancer susceptibility syndromes and the likelihood that an individual has a germline mutation in one of the various cancer susceptibility genes. To assist health care professionals in deciding when a cancer genetics consultation is appropriate, available reports were critically reviewed in order to develop a single set of risk assessment criteria.

Methods: The criteria were based on a comprehensive review of publications describing diagnostic criteria for hereditary cancer syndromes and risk to first degree relatives of cancer patients. Priority was given to diagnostic criteria from consensus statements (for example, those from the National Comprehensive Cancer Network). Expert opinion from study personnel was then used to adopt a single set of criteria from other publications whenever guidelines differed.

Results: Based on family history, a set of criteria was developed to identify patients at risk for a hereditary cancer susceptibility syndrome, patients with moderate risk who might benefit from increased cancer surveillance, and patients who are at average risk. The criteria were applied to 4360 individuals who provided their cancer family history between July 1999 and April 2002, using a touch screen computer system in the lobby of a comprehensive cancer centre. They categorised an acceptable number of users into each risk level: $14.9 \%$ high risk, $13.7 \%$ moderate risk, and $59.6 \%$ average risk; $11.8 \%$ provided insufficient information for risk assessment.

Conclusions: These criteria should improve ease of referral and promote consistency across centres when evaluating patients for referral to cancer genetics specialists.
$\mathrm{H}$ ealth care providers have been encouraged to collect and analyse systematically the family histories of cancer in their patients, so as to facilitate prevention efforts and screening of relatives. Further, "duty to warn" litigation $^{1}$ has underscored the importance of notifying cancer patients (and immediate family members) if they are at risk for a hereditary cancer susceptibility syndrome. This task usually involves, first, obtaining a cancer family history; second, determining whether a hereditary susceptibility exists; and third, communicating this risk assessment to patients and their families. To this end, health care providers are beginning to obtain cancer family histories from their patients in a concerted effort to provide risk assessment. Providers generally obtain information about first and second degree relatives affected by cancer, including the type of cancer and the age at diagnosis. For more information about taking a cancer family history, visit the National Cancer Institute Cancer Genetics PDQ at $<$ http://www.cancer. gov/cancerinfo/pdq/genetics/risk-assessment-and-counseling\# section $18>$. Interpretation of these family history data, however,remains thegreatest challenge tohealthcareproviders, who maynothave expertisein the area of cancergenetics. ${ }^{2}$

A major limitation of cancer family risk assessment has been the variability of the risk assessment criteria used among institutions and individual clinicians. Many centres do not have written risk assessment criteria and rely on the expert opinion of the individual performing the assessment. In some cases, there are explicit criteria for the assessment of hereditary risk that may be missed by a limited review of the family history. For example, hereditary non-polyposis colon cancer syndrome (HNPCC) is an inherited cancer syndrome characterised primarily by colorectal and endometrial cancers. If the assessment during an annual gynaecological examination or mammogram is restricted to questions about breast or ovarian cancer, it is possible that HNPCC families may go undetected.

In order to facilitate and provide consistency in risk assessment, we sought to develop a set of criteria for use by clinicians gathering cancer family history information. The criteria are currently being used at two separate comprehensive cancer centres which collect family history data in different ways-one with a touch screen computer and the other with computer scanned forms. It would be ideal if these criteria could be used in a wide variety of settings by anyone collecting cancer family history information.

\section{METHODS}

\section{Search strategy and selection criteria}

A literature search was conducted using the MeSH headings "genetic predisposition to disease," "genetic screening," "neoplasms," and "genetic counseling." Risk assessment criteria differed from study to study and most only addressed a single hereditary cancer susceptibility syndrome. The papers identified underwent critical review with priority given to:

- diagnostic criteria from consensus statements, for example the National Comprehensive Cancer Network, and so on;

- research studies providing empirical data on the likelihood of having a mutation in a cancer susceptibility gene;

Abbreviations: CRC, colorectal cancer; FDR, first degree relative; $\mathrm{HBOC}$, hereditary breast and/or ovarian cancer syndrome; HNPCC, hereditary non-polyposis colon cancer syndrome; LFL, Li-Fraumeni-like; LFS, Li-Fraumeni syndrome; MEN, multiple endocrine neoplasia; NCCN, National Comprehensive Cancer Network, SDR, second degree relative 
Table 1 Risk assessment criteria

\section{BREAST-OVARIAN}

Non-Jewish families

High risk breast-ovarian

Moderate risk breast

Moderate risk ovarian

BREAST-OVARIAN

Jewish families

High risk breast-ovarian

POLYPOSIS

Polyposis

PROSTATE

High risk prostate

Moderate risk prostate

MELANOMA

High risk melanoma

Moderate risk melanoma

LI-FRAUMENI SYNDROME

High risk Li-Fraumeni

Any of the following:

1 case of breast cancer $\leqslant 40$ y in an FDR or SDR

1 FDR or SDR with both breast and ovarian cancer, at any age

$\geqslant 2$ cases of breast cancer in FDRs or SDRs if one is diagnosed at $\leqslant 50 \mathrm{y}$ or is bilateral

1 FDR or SDR with breast cancer diagnosed at $\leqslant 50$ y or bilateral and 1 FDR or SDR with ovarian cancer

3 cases of breast and ovarian cancer (at least one case of ovarian cancer) in FDRs and SDRs

2 cases of ovarian cancer in FDRs and SDRs

1 case of male breast cancer in an FDR or SDR if another FDR or SDR has (male or female) breast or ovarian cancer

Any of the following

2 FDRs if both diagnosed between 51 and $60 y$

1 FDR and SDR (mother or sister and maternal aunt or maternal grandmother), if sum of their ages is $\leqslant 118 y$

1 FDR with ovarian cancer

Any of the following:

$\geqslant 1$ case of breast cancer $\leqslant 50 y$ in an FDR or SDR

$\geqslant 1$ case of ovarian cancer at any age in an FDR or SDR

$\geqslant 1$ FDR or SDR with breast cancer at any age if another FDR or SDR has

breast and/or ovarian cancer at any age

$\geqslant 1$ case of male breast cancer in an FDR or SDR

Any of the following:

3 FDRs or SDRs affected with any HNPCC associated cancers*; all cases can occur in one generation, no age restriction

1 FDR or SDR with two or more HNPCC associated cancers*

1 FDR with $C R C<50 y$

1 FDR with $C R C \geqslant 50$ and one SDR with CRC at any age

2 FDRs with $C R C \geqslant 50$ at any age

Any FDR or SDR with $>10$ polyps

Any of the following:

3 relatives affected, any age

2 relatives affected ( 2 FDRs or 1 FDR and 1 SDR), one diagnosed at $<60$ y Any of the following:

1 FDR diagnosed at $<60$ y

2 FDRs with PC diagnosed at $>60$ y

1 FDR and one SDR with PC diagnosed at $>60 y$

3 FDRs or SDRs affected with melanoma and or pancreatic cancer, at least two generations (must include more than one case of melanoma)

1 FDR or SDR with multiple primary melanomas

$\geqslant 1$ FDR with melanoma

All of the following:

1 FDR or SDR with sarcoma, brain, or adrenal cancer diagnosed at $<45 \mathrm{y}$; and

1 FDR or SDR with sarcoma, breast, brain, adrenal or leukaemia at any age; and

1 FDR or SDR with any cancer diagnosed at $<60$ y

\section{MULTIPLE ENDOCRINE NEOPLASIAS/THYROID CANCER}

High risk MEN 1

High risk thyroid/MEN 2

Moderate risk thyroid
2 cases of pancreatic (islet cell) cancer, parathyroid (hyperplasia) and/or pituitary adenoma in FDRs or SDRs (can be same person)

Any of the following:

2 cases of thyroid cancer in FDRs or SDRs

1 FDR or SDR with thyroid cancer and 1 FDR or SDR with parathyroid

(hyperplasia) or adrenal cancer (can be same person)

1 FDR with thyroid cancer 
Table 2 Consensus guidelines for hereditary breast-ovarian cancer

NCCN

1. Member of known BRCA1/BRCA2 kindred

2. Personal history of breast cancer

- Diagnosed age $\leqslant 40 y$, with or without family history

- Diagnosed age $\leqslant 50$ y or bilateral, with $\geqslant 1$ close blood relative with breast cancer or $\geqslant 1$ close blood relative with ovarian cancer

- Diagnosed at any age, with $>2$ close relatives with ovarian cancer at any age, or breast cancer, especially if $\geqslant 1$ woman is diagnosed before age 50 y or has bilateral disease

- Close male blood relative has breast cancer

- Personal history of ovarian cancer

- If of Ashkenazi Jewish descent and diagnosed age $\leqslant 50 y$, no additional family history required or at any age if positive family history of breast and/or ovarian cancer

3. Personal history of ovarian cancer

- One or more close relatives with ovarian cancer

- One or more close female relatives with breast cancer at age $\leqslant 50$ y or bilateral breast cancer

- Two or more close relatives with breast cancer

- One or more close male relatives with breast cancer

- If of Ashkenazi Jewish descent, no additional family history is required

4. Personal history of male breast cancer plus one or more of the following:

- One or more close male relatives with breast cancer

- One or more close female relatives with breast or ovarian cancer

- If of Ashkenazi Jewish descent, no additional family history is required

5. Family history only

- Close family member meeting any of the above criteria.

\section{ACMG/NYS}

1. Family member with an identified mutation

2. Three or more affected FDRs or SDRs on the same side of the family, regardless of age at diagnosis

3. Patient diagnosed with breast cancer at $\leqslant 45$ y

4. One or more cases of ovarian cancer at any age and $\geqslant 1$ case of breast cancer at any age

5. Multiple primary cancers or bilateral breast cancer in patient or family member

6. One or more cases of male breast cancer

7. If of Ashkenazi Jewish descent, 1 close relative with breast or ovarian cancer

Kaiser Permanente

1. Women or men with a maternal or paternal relative who has previously been tested and found to have a clinically significant alteration in a breast cancer (BRCA) gene.

2. Women or men with a personal and family history of breast and/or ovarian cancer in maternal or paternal relative(s) as defined by at least one of the following:

- Women with breast cancer at $\leqslant 49$ plus one or more FDR or SDR with breast cancer diagnosed at $\leqslant 49$ y

- Women with breast cancer at any age plus:

- Breast cancer in $\geqslant 2$ FDRs or SDRs where any of the affected relatives is diagnosed at $\leqslant 49$ y

- Ovarian cancer in $\geqslant 1$ FDR or SDR

- Women with ovarian cancer plus

- Breast cancer in $\geqslant 1$ FDR or SDR

- Ovarian cancer in $\geqslant 1$ FDR or SDR

- Men with breast cancer plus breast and/or ovarian cancer in $\geqslant 1$ FDR or SDR

3. Women with a personal history (but no family history) of breast and/or ovarian cancer as defined by at least one of the following:

- Breast cancer at $\leqslant 29$ y

- Breast cancer $<40$ y and of Ashkenazi Jewish descent

- Ovarian cancer and of Ashkenazi Jewish descent

- Breast cancer and ovarian cancer

- Multiple primary breast cancers

4. Women or men with a family history (but no personal history) of breast and/or ovarian cancer in maternal or paternal relatives as defined by at least one of the following:

- Breast cancer in at least:

- 2 FDRs or SDRs both diagnosed at $\leqslant 49$ y and at least one of the relatives is a FDR

- 3 FDRs or SDRs with $\geqslant 1$ relative diagnosed at $\leqslant 49$ y

- Ovarian cancer in $\geqslant 2$ FDRs or SDRs

- Breast cancer in $>1$ FDR or SDR and ovarian cancer in $\geqslant 1$ FDR or SDR

ACMG/NYS, American College of Medical Genetics and New York State Department of Health; BRCA, breast cancer mutation; NCCN, National Comprehensive Cancer Network.

beyond that recommended for the general population. Consideration was given to the availability and efficacy of cancer surveillance procedures. Thus cancers omitted from the moderate risk criteria include pancreatic, lung, stomach, oesophagus, small intestine, brain, and haematological malignancies. It is recognised that there are screening methods for some of these cancers (for example, upper endoscopy for gastric cancer and spiral computed tomography for lung cancer detection); however, they are not of proven efficacy in moderate risk individuals. In addition, there are other cancers for which the screening guidelines for the general population (from resources such as the American Cancer Society) are also appropriate for individuals at twice the general population risk for developing the cancer. These include cervical, endometrial, and non-melanoma skin cancers.

Individuals who do not meet the high risk or moderate risk criteria, meet the average risk criteria by default. These individuals should follow guidelines for cancer screening in the general population (the US guidelines written by the American Cancer Society can be found on-line at http:// www.cancer.org).

\section{RESULTS}

The review process resulted in a set of risk assessment criteria (table 1), with the rationale summarised below, by organ 
Table 3 Derivation of age formula for breast cancer moderate risk criteria ( $>20 \%$ ) using Claus tables

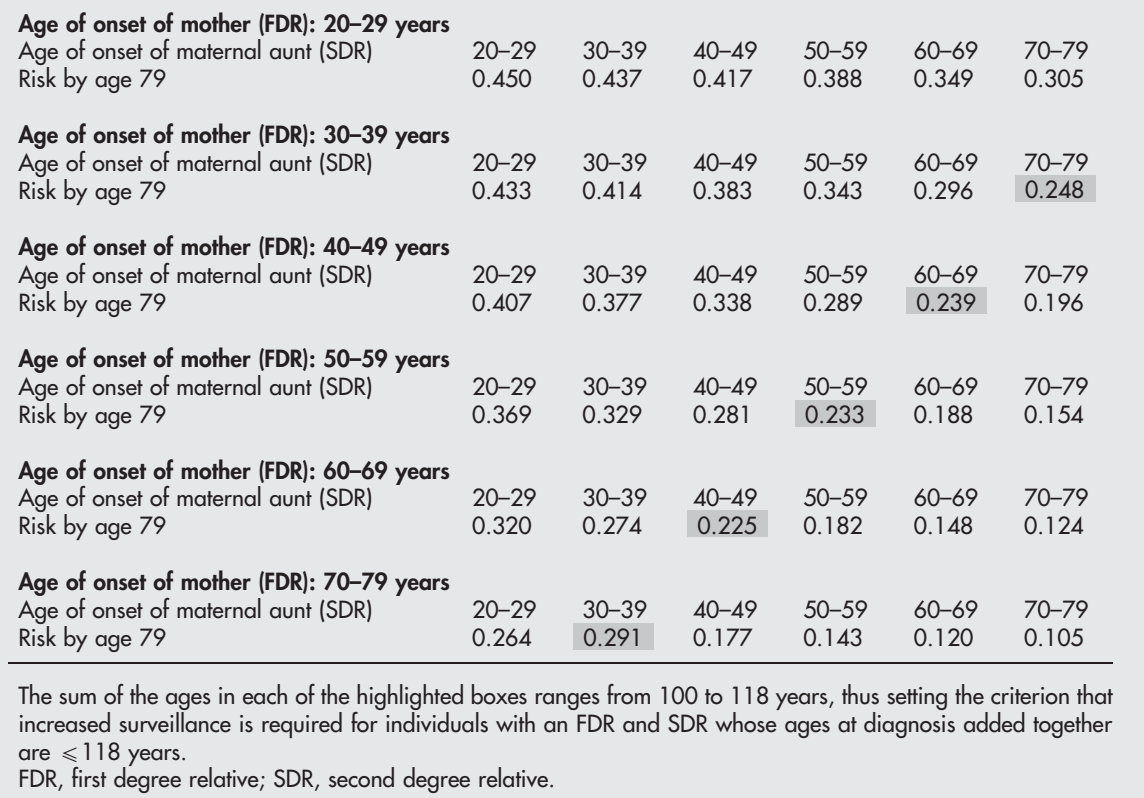

systems. In general, with rare exceptions, selection of high risk criteria reflect the known hallmarks of any hereditary cancer susceptibility syndrome-young age at diagnosis, multifocal tumours, bilaterality, presence of more than one associated cancer, and multiple affected members in a family.

\section{Risk assessment criteria for breast and ovarian cancers}

The genetic differential diagnosis for breast cancer includes hereditary breast and/or ovarian cancer syndrome (HBOC), Cowden syndrome, and Li-Fraumeni syndrome. ${ }^{4}$ In contrast, the genetic differential diagnosis for ovarian cancer includes HBOC and HNPCC. Germline mutations in BRCA1 or BRCA2 genes are associated with $\mathrm{HBOC}$, believed to be the most common inherited breast cancer syndrome. There is an extensive literature on risk assessment criteria for breast and ovarian cancers. Professional society guidelines are based on empirical data regarding the likelihood that a particular family history can be attributed to a BRCA mutation; therefore these professional guidelines were used for the high risk criteria. Epidemiological studies estimating the risk that an individual will develop breast or ovarian cancer based on her family history were used to develop the moderate risk criteria.

High risk breast-ovarian cancer criteria (non-Jewish families)

Because of the high frequency of three specific BRCAl and $B R C A 2$ founder mutations among the Ashkenazim (with a $2.5 \%$ likelihood of having one of these mutations in the general Ashkenazi Jewish population), criteria for people of Jewish descent are reviewed separately (below).

There are several professional society guidelines that describe individuals at increased risk for HBOC. The National Comprehensive Cancer Network (NCCN)—an affiliation of 17 US cancer centres given comprehensive status by the US National Cancer Institute-has developed guidelines for genetic/familial high risk screening using a committee of cancer genetics experts from the member institutions. ${ }^{5}$ The guidelines are very similar to those developed by the Kaiser Permanente managed care organisation ${ }^{6}$ and the American College of Medical Genetics (ACMG) and New York State Department of Health ${ }^{7}$ (table 2).

Criteria for referral of solitary presentations of breast cancer rests on whether the a priori risk of finding a germline mutation is $\geqslant 10 \%$ when diagnosed before a certain age. The main difference between the guidelines is cut off age at diagnosis: 30 years (Kaiser-Permanente), 40 years (NCCN), and 45 years (ACMG). The empirical data are variable, ranging from a $5.9 \% B R C A 1$ and $B R C A 2$ mutation frequency in women diagnosed before the age of $36^{8}$ to $9.4 \%$ of those diagnosed before $35 .^{9}$ Mutation prevalence tables from the only laboratory providing clinical BRCA testing in the USA indicate that $7.6 \%$ of women with breast cancer under the age of 50 have a mutation, even if there is no family history of ovarian cancer or breast cancer under the age of $50 .{ }^{10}$ From these population based studies, an age cut off of 35 years may be appropriate given the proximity to a $10 \%$ a priori risk for mutation. However, in view of the fact that research studies often use detection technologies that may only be $60-90 \%$ sensitive, ${ }^{11}$ the mutation likelihood of those diagnosed under the age of 35 is likely to be falsely diminished and so an age cut off of 40 is adopted here.

In addition to young age at diagnosis, our high risk breastovarian criteria also consider the presence of multiple affected members in a family, ovarian cancer, male breast cancer, and bilateral breast cancer. The three Society guidelines recommend referral of individuals with three family members affected with breast or ovarian cancer or both (the NCCN requires at least one of the diagnoses to be ovarian cancer or a breast cancer that is diagnosed under the age of 50 or bilateral, while the others do not). The high risk breastovarian criteria presented here mirror the NCCN criteria.

Models based on data derived from multiple studies ${ }^{12-14}$ are available to estimate probabilities of detecting BRCA mutations depending on personal or family history of cancer. While these models are reasonable predictors of the likelihood that a patient has a BRCA mutation, they have to be used with professional judgment in the context of broad and in-depth knowledge of the cancer genetics literature. For 
Table 4 Hereditary non-polyposis colorectal cancer guidelines

Original Amsterdam criteria (Amsterdam criteria I)

There should be at least three relatives with colon cancer and

- one should be a first degree relative of the other two;

- at least two successive generations should be affected

- at least one should be diagnosed before the age of 50

- familial adenomatous polyposis should be excluded;

- tumours should be verified by pathological examination.

Revised Amsterdam criteria (Amsterdam criteria II)

There should be at least three relatives with an HNPCC associated cancer

(cancer of the colorectum, endometrium, small bowel, ureter, or renal

pelvis) and

- one should be a first degree relative to the other two;

- at least two successive generations should be affected;

- at least one should be diagnosed before the age of 50;

- familial adenomatous polyposis should be excluded

- tumours should be verified by pathological examination.

Bethesda guidelines

- Individuals with cancer in families that meet the Amsterdam criteria.

- Individuals with two HNPCC related cancers, including synchronous and metachronous colorectal cancers or associated extracolonic cancers*

- Individuals with colorectal cancer and a first degree relative with colorectal cancer and/or HNPCC related extracolonic cancer and/or a colorectal adenoma: one of the cancers diagnosed at age $<45 y$, and the adenoma diagnosed at age $<40 y$

- Individuals with colorectal cancer or endometrial cancer diagnosed at age $<45$ y

- Individuals with right sided colorectal cancer with an undifferentiated pattern (solid/cribriform) on histopathology diagnosed at age $<45$ y

- Individuals with signet ring cell type colorectal cancer diagnosed at age $<45$

- Individuals with adenomas diagnosed at age $<40$ y

AGA guidelines (Bethesda criteria-modified)

- Amsterdam I criteria

- Individuals with two HNPCC cancers (including synchronous) metachronous colorectal cancers.

- Individuals with CRC and an FDR with CRC and/or HNPCC extracolonic cancer and/or colorectal adenoma (cancer $<50$ y and adenoma $<40$ y)

- CRC or endometrial cancer $<50$ y

- Right sided CRC with undifferentiated pattern on histology $<50$ y

- Signet cell type CRC $<50$ y

- Colorectal adenoma $<40$ y

*Endometrial, ovarian, gastric, hepatobiliary, or small bowel cancer or transitional cell carcinoma of the renal pelvis or ureter.

CRC, colorectal cancer; FDR, first degree relative; HNPCC, hereditary

non-polyposis colon cancer syndrome; $y$, years.

example, the Couch model requires averaging the ages of breast cancer diagnoses in a given family and can only be used for families with at least two cases of breast cancer. Further, these models do not lend themselves to large scale screening efforts. As a result, we recommend that individuals familiar with their limitations apply these models

\section{Moderate risk breast cancer criteria (non-Jewish individuals)}

The two most frequently used models for predicting lifetime risk for developing breast cancer are the Gail model from the breast cancer detection and demonstration project ${ }^{15-17}$ and the Claus data from the cancer and steroid hormone (CASH) study.$^{18}{ }^{19}$ As our risk assessment model is based solely on family history, we do not collect the information necessary to do the Gail risk calculation (age at menarche, parity, age at first childbirth, number of breast biopsies, and presence of atypia in these biopsies). We have elected to use the CASH data instead, as they incorporate more extensive information about family history and have been found to offer the most comprehensive assessment of family history for women with one or more first or second degree relatives with breast cancer. ${ }^{2021}$ These data do not in any way reflect the likelihood that a particular individual has a BRCAl or BRCA2 gene mutation. The Claus tables were used to create the moderate risk breast cancer criteria, targeting women with a relative risk of $\geqslant 2.0$ (or a lifetime risk of $\geqslant 20 \%$ ) for developing breast cancer. For women with a single first degree relative affected by breast cancer, the relative risk exceeded 2.0 only when the relative is diagnosed under the age of 30. As we classify anyone with a first or second degree relative with breast cancer diagnosed under the age of 40 as high risk, this criterion is not included among the moderate risk criteria. Women with two first degree relatives diagnosed with breast cancer had a lifetime risk exceeding $20 \%$ when one of these relatives was diagnosed under the age of 50 , regardless of the age of diagnosis of the second one; however, this would be classified as high risk, so it was not included in the moderate risk category. If both first degree relatives were diagnosed between the ages of 51 and 60 , the relative risk exceeded 2.0 and this would be considered a moderate risk. For women with a first degree relative and a maternal second degree relative (maternal aunt or maternal grandmother) affected by breast cancer, the relative risk for developing breast cancer exceeded 2.0 when the sum of the ages of both these relatives was $\leqslant 118$ (table 3 ). Review of the Claus tables for two second degree relatives and for the combination of one maternal first degree relative and one paternal second degree relative indicates that one of the relatives would need to be diagnosed under the age of 50 to exceed a relative risk of 2.0, thus meeting the high risk breast criteria. As a result, these criteria were not included in the moderate risk criteria.

\section{Moderate risk ovarian cancer criteria (non-Jewish families)}

In 1992, Kerlikowske et al reviewed all case-control studies of family history as a risk factor for ovarian cancer. ${ }^{22}$ They found that the relative risk for developing ovarian cancer among women with a first degree relative with ovarian cancer ranged from 1.9 to 3.6. As this meets our minimum relative risk of 2.0, this is the criterion adopted for moderate risk ovarian cancer. Women with a first degree relative with ovarian cancer who do not meet the high risk guidelines should discuss increased ovarian cancer surveillance with their physician. While the efficacy of ovarian cancer surveillance is unproven, some women at this level of risk might consider prophylactic oophorectomy.

\section{High risk breast-ovarian cancer criteria (Jewish families)}

There are three founder mutations in the BRCA genes found in $2.5 \%$ of the Ashkenazi Jewish population. ${ }^{23}$ As a result, a Jewish individual has a greater than $10 \%$ likelihood of having a BRCA mutation with less personal and family history of breast and ovarian cancer than a non-Jewish individual. Data from the New York breast cancer study indicate that $10.2 \%$ of Jewish women with breast cancer have one of the three founder mutations, regardless of family history. ${ }^{24}$ Thus the high risk breast-ovarian cancer risk assessment criteria differ for Jewish and non-Jewish individuals. The high risk criteria adopted for use with Jewish families are also taken from the NCCN guidelines (table 2). Given the extensive nature of the high risk breast-ovarian criteria for Jewish individuals, there is no moderate risk breast or ovarian cancer category.

\section{Colon and other HNPCC associated cancer criteria High risk HNPCC criteria}

Because HNPCC is believed to be the most common hereditary cause of colon cancer, the general colon cancer 
risk criteria are built around established guidelines for its diagnosis (table 4). The International Consortium on Hereditary Nonpolyposis Colorectal Cancer (ICG-HNPCC) established a set of clinical diagnostic criteria, known as the Amsterdam criteria, to promote consistency among research studies. ${ }^{25}$ The Amsterdam criteria have been criticised for not taking into account the extracolonic cancers that are often associated with HNPCC. To resolve this problem, new clinical criteria (Amsterdam II criteria) were proposed $^{26}$ to identify families that are very likely to have HNPCC. However, these criteria are not intended to serve as a guide to exclude families from cancer genetic consultation or mutation analysis. Therefore less restrictive criteria were adopted for the high risk colon category by extending the Amsterdam II criteria to include stomach, ovarian, and pancreatic cancers in the list of extracolonic cancers, because of data consistently associating them with HNPCC. Ureteric and renal pelvic cancers are also HNPCC associated cancers but are too specific to be included on most cancer family history questionnaires. "Kidney" cancer was accepted in lieu of these cancers for the purposes of mass screening. The exact subtype can be determined at subsequent interactions. Finally, for families with three cases of HNPCC associated cancers, we removed the age (one diagnosis under age 50) and multiple generation requirements in order to be more inclusive.

Two additional criteria were adopted for the high risk HNPCC category. These include any family with a first degree relative diagnosed with colon cancer under the age of 50 or a first or second degree relative with two or more HNPCC associated cancers. This is based on the large population based HNPCC screening study in Finland. ${ }^{27}$ Using these criteria, 27 of the 28 patients with colorectal cancer found to carry HNPCC mutations in that study would have been identified. Moreover, the Bethesda guidelines suggest that further evaluation for HNPCC (through microsatellite instability testing) is warranted in any individual with more than one HNPCC associated cancer and for anyone diagnosed with colon cancer under the age of $45 .^{28}$ The Bethesda criteria were recently found to have the highest sensitivity in detecting mutation positive HNPCC cases when compared with either of the two Amsterdam criteria. ${ }^{29}$ The American Gastroenterology Association adjusted the Bethesda criteria to suggest microsatellite instability for any colorectal cancer diagnosed under age 50, providing further support for this age cut off. ${ }^{30}$ At a recent follow up meeting (11-13 December 2002) for the revision of the Bethesda guidelines, it was decided to increase the age from 45 to 50. For the criteria presented here, the age of 50 was selected to maintain sensitivity while balancing the need to limit unnecessary "false positive" referrals. Around 8\% of individuals diagnosed with colorectal cancer are under the age of 50 according to the population based series of colorectal cancer cases in Finland. ${ }^{31}$

\section{Moderate risk colon cancer criteria}

The population data regarding lifetime risks for colorectal cancer and not the likelihood of having an HNPCC gene mutation were reviewed to develop the moderate risk category. It has been found that an individual with one first degree relative diagnosed with colorectal cancer under the age of 45 has a relative risk of 3.7 to 6.4 for developing this condition. $^{32} 33$ If the relative with colorectal cancer was diagnosed after the age of 45 , the relative risk decreased to 1.8 to 2.7. For individuals with two first degree relatives diagnosed at any age, the relative risk was 5.7.33 Individuals with one first degree and one second degree relative diagnosed with colorectal cancer had a relative risk of $4.16 .^{33}$ Our moderate risk criteria, therefore, include individuals with two first degree relatives or one first degree and one second degree relative with colorectal cancer, when the first degree relative is diagnosed at age 50 or greater (otherwise they would meet the high risk criteria).

\section{High risk polyposis}

It is advisable to include a question in all cancer family history collection tools to ascertain whether any family members have been diagnosed with polyposis (defined loosely as more than 10 colonic polyps) in their lifetime. Anyone answering in the affirmative should be referred for cancer genetics consultation. Pathology reports can be reviewed and a physical examination done to evaluate the family further for the possibility of familial adenomatous polyposis, MYH polyposis, Peutz-Jeghers syndrome, juvenile polyposis, mixed polyposis, or Cowden syndrome/BannayanRuvalcaba-Riley syndrome.

\section{Prostate cancer criteria}

\section{High risk prostate cancer criteria}

Researchers are actively studying families with multiple cases of prostate cancer in a search for the genes responsible for hereditary prostate cancer. This search has been complicated by the discovery that many loci ( $H P C X,{ }^{34} P C A P,{ }^{35}$ and $\left.C A P B^{36}\right)$ are involved. To date, only two genes-HPCI/RNASEL ${ }^{37}{ }^{38}$ and $H P C 2 / E L A C 2^{39}{ }^{40}$ - have been isolated, but each accounts for very few hereditary cases. The high risk prostate criteria are based on the fact that families with more than three affected individuals are eligible for prostate cancer genetic research studies and could benefit from cancer genetics consultation. The relaxed criteria requiring two affected individuals (one diagnosed under the age of 60) are included in order to accommodate possible X linked inheritance patterns; these could limit the number of affected individuals because of the lack of male to male transmission and the unaffected status of obligate carrier mothers.

\section{Moderate risk prostate cancer criteria}

The moderate risk prostate criteria are based on population studies of prostate cancer risk. These studies suggest that first degree relatives of prostate cancer patients have a relative risk of 2.0 to 3.2 for developing the disease..$^{41-43}$ Although prostate cancer is more common in AfricanAmericans in the USA, the relative risk for developing prostate cancer when a first degree relative was affected was found to be similar among black and white individuals, so our risk assessment criteria do not take race into account. ${ }^{44}$ These relative risks infer that individuals with a single first degree relative affected by prostate cancer should meet the moderate risk criteria; however, we elected to add an age restriction so that individuals only meet this criterion if the first degree relative was diagnosed under the age of 60. In the USA, the American Cancer Society recommends that men begin prostate cancer screening at age 50. As it is generally agreed that surveillance should begin at least 10 years before the earliest diagnosis in the family, individuals would only need to begin prostate cancer screening early (before the age of 50) if they have a first degree relative diagnosed under the age of 60 .

Steinberg et al also found a relative risk of 4.9 for individuals with two first degree relatives affected by prostate cancer, and 8.8 for individuals with one first degree and one second degree relative affected. ${ }^{42}$ Given these high relative risks $(>2.0)$ for developing prostate cancer, the moderate risk criteria include both individuals with two first degree relatives with prostate cancer over the age of 60, and also those with one first degree and one second degree relative affected by prostate cancer over the age of 60 . 


\section{Melanoma criteria}

High risk melanoma criteria

A review by the Melanoma Genetics Consortium found that $20-40 \%$ of families with three or more affected first degree relatives have a mutation in the $C D K N 2 A$ gene, while mutations were only found in $5 \%$ of families with two affected first degree relatives. ${ }^{45}$ Approximately $15 \%$ of individuals with multiple primary melanomas will be found to have a $C D K N 2 A$ mutation. ${ }^{46}$ Based on these data, our high risk criteria require at least three relatives affected by melanoma in at least two generations, or any individual with multiple primaries. In addition, there is evidence that mutations in the $C D K N 2 A$ gene also lead to an increased risk for pancreatic cancer. ${ }^{47} 48$ Accordingly, pancreatic cancers are included in the risk criteria.

\section{Moderate risk melanoma criteria}

Population studies have shown that individuals with one or more first degree relatives affected by melanoma have a relative risk of 2 to 3 for developing melanoma. ${ }^{49}$ Therefore increased surveillance is recommended for anyone with at least one first degree relative with melanoma. Increased surveillance for melanoma is non-invasive and includes more frequent clinical skin examinations, full body photography, and routine self examination, more frequent clinical skin examinations, and full body photography when indicated.

\section{Li-fraumeni criteria}

High risk Li-Fraumeni syndrome criteria

The classic diagnostic criteria for the Li-Fraumeni syndrome (LFS) are based on the original epidemiological studies of LiFraumeni kindreds. ${ }^{50-52}$ Families meeting these criteria have a $71 \%$ chance of having a germline TP53 mutation. ${ }^{53} 54$ It is quite rare for a family to meet the classic definition of LFS, however, so broader criteria were developed to ensure that all potential LFS families are detected. Li-Fraumeni-like (LFL) families have been defined in many different ways. ${ }^{53} 55$ Depending on the definition of LFL used, as many as $22 \%$ are found to have germline mutations in TP53. For these high risk Li-Fraumeni criteria, the NCCN LFL criteria were adopted. ${ }^{5}$ As it is unlikely that a family history questionnaire will identify the specific adrenal pathology associated with LFS (adrenocortical tumours), our criteria allow for any type of adrenal tumour. However, if there is a documented case of adrenocortical carcinoma, the family should be referred for cancer genetics consultation (below).

\section{Multiple endocrine neoplasias}

It is difficult to provide an assessment for the multiple endocrine neoplasia (MEN) syndromes on the basis of information obtained in a family history collection tool because of the importance of the histopathology of each of the component tumours. For example, it is reasonable to ask about a family history of thyroid cancer but one cannot assume that family members would know the specific histology (papillary, follicular, or medullary). Similarly, one cannot easily assess by questionnaire whether a pancreatic cancer is an adenocarcinoma or an islet cell tumour, or whether an adrenal tumour is a phaeochromocytoma or another subtype. In addition, many of the component tumours are not malignant—such as parathyroid hyperplasia and pituitary adenomas-so individuals may not include these diagnoses in a cancer history.

\section{High risk MEN 1 criteria}

As the diagnosis of MEN 1 is based on the presence of pancreatic islet cell tumours, pituitary adenomas, and parathyroid hyperplasia, the risk assessment criteria attempt to identify families with at least two of these features. MEN 1 has historically been diagnosed when two close relatives or a single individual have at least two of the principal clinical features. ${ }^{56}{ }^{57} \mathrm{~A}$ cancer genetics consultation is appropriate for families with two cases of pancreatic (islet cell) cancer, parathyroid (hyperplasia), or pituitary adenoma in first degree or second degree relatives (both diagnoses can occur in the same person).

High risk thyroid cancer criteria (MEN 2 and familial non-medullary thyroid cancer)

The features of MEN 2 include medullary thyroid cancer, phaeochromocytomas, and parathyroid hyperplasia. If a family has a single case of medullary thyroid cancer they should be referred for cancer genetic consultation because the likelihood of having a RET gene mutation exceeds $10 \% .^{58}$ However, it would be unusual for individuals to be able to report the exact histology of a relative's thyroid cancer. As the medullary histology is rare among all thyroid cancers, it would not be prudent to refer every person who had a single relative with "thyroid cancer" for cancer genetic consultation. For this reason, when one is unsure of the thyroid cancer histology, one additional feature is required for a family to be referred for a cancer genetics consultation. Even if the thyroid cancers in these families are non-medullary, they may be eligible for research studies aiming to identify the genes responsible for familial non-medullary thyroid cancer.

\section{Moderate risk thyroid cancer criteria}

It is known that individuals with a single first degree relative diagnosed with thyroid cancer have a relative risk of $>2.0$ for developing thyroid cancer regardless of subtype. ${ }^{59} 60$ These individuals may want to talk to their physician about increased thyroid cancer surveillance that might include annual physical examination with appropriate biochemical testing and thyroid ultrasound as indicated.

\section{Single cases of cancer requiring cancer genetics consultation}

There is evidence that a single individual diagnosed with medullary thyroid cancer. $^{58}$ adrenocortical carcinoma, ${ }^{6162}$ phaeochromocytoma, ${ }^{63}$ or paraganglioma (including carotid body tumours and glomus tumours $)^{64}$ has $a \geqslant 10 \%$ chance of having a hereditary cancer susceptibility syndrome. Therefore, in keeping with the other high risk categories, we recommend that individuals diagnosed with the above cancers, or those with a first degree relative diagnosed with these cancers, be referred for cancer genetics consultation regardless of their age at diagnosis or their family history.

Wilms' tumour and retinoblastoma are known to be hereditary when bilateral or multifocal. As this is difficult to determine by questionnaire, one can either refer all individuals with these rare tumour types or risk missing some hereditary cases. Thus we have elected to suggest referral of all patients with a diagnosis of these tumours in themselves or a first degree relative for further consultation. Pathology reports can be reviewed at that time to determine whether or not the tumours are likely to be hereditary.

\section{Familial aggregation of cancer}

This broad category is critical for identifying families with cancer clusters suggestive of a hereditary predisposition. A cancer cluster can loosely be defined when a family has more cases of a particular cancer than one would expect to see by chance alone. To capture these clusters, the familial aggregation criteria state that any family with three cases (in first or second degree relatives) of the same malignancy on one side of the family should be considered high risk and 
be referred for a cancer genetics consultation. There are known cancer predisposition genes for some of these clusters-for example, basal cell naevus syndrome $(P T C H)$, familial gastric cancer $(C D H 1)$, familial papillary renal cell carcinoma (MET), and renal cell cancers associated with Von Hippel Lindau disease (VHL) and Birt-Hogg-Dubé syndrome $(B H D)$. For other cancer clusters, the responsible genes are yet to be identified. In these cases, families can be offered participation in research studies and familial tumour registries (that is, familial non-papillary renal cell carcinomas, familial pancreatic cancer, familial testicular cancer, familial oesophageal cancer, and familial haematological malignancies).

\section{Other hereditary cancer predisposition syndromes}

Cancer susceptibility syndromes not specifically addressed in these risk assessment criteria include Cowden syndrome, Von Hippel Lindau syndrome, tuberous sclerosis, neurofibromatosis, Carney complex, multiple osteochondromatosis, familial paraganglioma, Werner syndrome, and chromosome fragility syndromes (ataxia-telangiectasia, Bloom syndrome, Fanconi anaemia, and xeroderma pigmentosum). These syndromes include many non-cancer features and physical stigmata that are impossible to address in a large scale family history survey format. It is likely that families with Cowden syndrome could be identified by the high risk polyposis, thyroid, or breast-ovarian criteria. ${ }^{65}$ Some families with Von Hippel Lindau syndrome could be identified by a familial aggregation of renal cancers or apparently isolated presentations of phaeochromocytoma. In addition, the chromosome fragility and progerioid syndromes, Werner syndrome, and Rothmund-Thomson syndrome are usually autosomal recessive conditions where the diagnosis is made on the basis of dysmorphic features in the proband. Often only one family member is affected, making it difficult to detect these patients from their cancer family history.

\section{Use of the risk assessment criteria}

Two free standing family history risk assessment units using touch screen computer technology have been placed in the lobby of the James Cancer Hospital/Comprehensive Cancer Center and the JamesCare Dublin ambulatory care facility. Patients, family members, or passers by can use these machines on a voluntary basis to provide information about their personal cancer history and their family history of cancer in first and second degree relatives. Information on family history was provided by 4360 users between mid-1999 and April 2002. These risk assessment criteria were applied and users were categorised into high, moderate, and average risk groups. Of all users, 651 (14.9\%) were found to be high risk, 598 (13.7\%) were found to be moderate risk, and 2598 $(59.6 \%)$ were found to be average risk, based on these criteria. As $5-10 \%$ of most cancers are thought to be hereditary (that is, high risk), while another 15\% are familial (moderate risk), we feel that these criteria were validated in practice. It is important to note that $513(11.8 \%)$ of the users provided insufficient information (generally unfinished entries) to assess risk. If these users all fell into the high risk category, it is possible that the criteria are too loose and lead to over-referral for cancer genetics consultation. However, in clinical practice, criteria which lead to "overreferral" are more conservative than those that miss true high risk cases. Nonetheless, the criteria will need to be validated in other settings to ensure wide scale applicability.

\section{DISCUSSION}

We have outlined the development of a set of criteria for use in assessing the cancer family history. An attempt was made to include all known hereditary cancer susceptibility syndromes in the development of risk assessment criteria. The criteria were developed for use with a computer assisted or paper family history questionnaire. There are limits to the information obtained by the usual collection tools that affect the ability to screen for certain syndromes (for example, some require a physical examination). Furthermore, most individuals cannot provide information on the exact histological subtypes of cancer. Risk assessment criteria must accommodate such limitations, always erring on the side of the highest risk scenario, so that families with hereditary cancer susceptibility syndromes are not missed. Practitioners who elicit a family history directly from an individual may be able to overcome the limitations.

These criteria do not address lifestyle and other epidemiological cancer risk factors. As a result, individuals are not given precise quantitative lifetime risks for cancer. Instead, they are placed in the general risk categories of high risk, moderate risk, and average risk, based only on their family history. The limitations of the risk assessment can be discussed in the risk notification communication process. In addition, family histories are dynamic and need to be updated regularly because additional relatives may be diagnosed with cancer since the last "risk assessment" occurred.

The importance of documentation of recommendations for both cancer genetics consultation and appropriate cancer surveillance based on family history assessment cannot be overemphasised. Identifying high risk families can save lives. For example, if a MEN 2A family is identified, counselling and genetic testing will lead to prophylactic thyroidectomy in mutation positive children in the family. This can prevent the development of medullary thyroid cancer. ${ }^{66}$ Likewise, there is evidence that beginning colonoscopies earlier and repeating them more often will dramatically reduce (and maybe eliminate) deaths from colon cancer in HNPCC families. ${ }^{67}$ This should apply to individuals meeting moderate risk colon cancer criteria as well.

There will not be 100\% compliance with the recommendation for a cancer genetics consultation. ${ }^{68}$ Thus high risk patients must be alerted to the risk for all cancers associated with a hereditary cancer syndrome. This is especially important because many families with site specific cancers are not aware of the increased risks for other associated cancers.

While published reports have defined some of the hereditary cancer syndromes, risk assessment criteria vary and expert opinion was also critical in the development of these criteria. Thus formal molecular based validation is necessary. Large scale validation may best be undertaken by an organisation such as the NCCN or a large consortium. Ideally, molecular analysis of large populations should be used to determine the percentage of hereditary cancer syndrome families that would be identified by and missed by the high risk criteria.

Cancer risk assessment criteria will continue to evolve as the definitions of hereditary cancer susceptibility syndromes are further refined. Adoption and oversight by a national body would promote the timely revision and standardisation of the risk assessment criteria as new cancer syndromes are discovered and our current knowledge changes. As risk assessment is only as accurate as the family history provided, the importance of documentation is evident.

Increasing numbers of clinicians are striving to document adequate family history information to determine whether a hereditary cancer susceptibility exists, and to notify patients of their risk assessment. While the family history collection tools and means of risk notification may vary, the risk assessment criteria should be standardised. This review 
presents the first comprehensive evidence based risk assessment criteria for hereditary cancer syndromes, which constitute a first approximation of a uniform approach to familial cancer risk assessment that is usable in clinical practice.

\section{ACKNOWLEDGEMENTS}

We thank Albert de la Chapelle, Carrie Drovdlic, Rob Pilarski, and Rebecca Nagy for critical review of the manuscript. We are grateful to Karen Brown, Beth Peshkin, Charlene Schulz, and Lauren Scheuer, who worked on the early prototypes of cancer family history screening tools. This work was partially funded by National Cancer Institute grant P30CA16058 (to The Ohio State University Comprehensive Cancer Center) and generous donations from the Brown family in memory of Welton D Brown (to CE). CE is a recipient of the Doris Duke distinguished clinical scientist award.

\section{Authors' affiliations}

H Hampel, K Sweet, J A Westman, C Eng, Clinical Cancer Genetics and Human Cancer Genetics Programs, The Ohio State University, Columbus, Ohio, USA

K Offit, Clinical Genetics Service, Department of Medicine, Memorial Sloan-Kettering Cancer Center, New York, NY, USA

\section{REFERENCES}

1 Severin MJ. Genetic susceptibility for specific cancers: medical liability of the clinician. Cancer 1999;86(8):1744-9.

2 Sweet K, Bradley TL, Westman JA. Identification and referral of families at high risk for cancer susceptibility. J Clin Oncol 2002;20:528-37.

3 Oncology ASoC. Statement of the American Society of Clinical Oncology: Genetic testing for cancer susceptibility. J Clin Oncol 1996;14:1730-6.

4 Emery J, Lucassen A, Murphy M. Common hereditary cancers and implications for primary care. Lancet $2001 ; 358: 56-63$.

5 Daly M. NCCN Practice guidelines: genetics/familial high-risk cancer screening. Oncology 1999;13:161-86.

6 Kutner SE. Breast cancer genetics and managed care: the Kaiser Permanente experience. Cancer 1999;86S: 1750-4.

7 ACMG, NYS Health Department. Genetic susceptibility to breast and ovarian cancer: assessment, counseling and testing guidelines, 1999. http:// www.health.state.ny.us/nysdoh/cancer/obcancer/contents.htm.

8 Peto J, Collins N, Barfoot R, Seal S, Warren W, Rahman N, Easton DF, Evans C, Deacon J, Stratton MR. Prevalence of BRCA1 and BRCA2 gene mutations in patients with early onset breast cancer. J Natl Cancer Inst 1999;91:943-9.

9 Malone KE, Daling JF, Neal C, Suter NM, O'Brien C, Cushing-Haugen K, Jonasdottir TJ, Thompson JD, Ostrander EA. Frequency of BRCA1/BRCA2 mutations in a population-based sample of young breast carcinoma cases. Cancer 2000;88:1393-402.

10 Myriad Genetic Laboratories I. mutation prevalence tables. http:// www.myriad.com/gtmp.html. July 1, 2003 [update].

11 Eng C, Brody LC, Wagner TMU, Devilee P, Szabo C, Tavtigian SV, Nathanson KL, Ostrander EA, Frank TS, Consortium SCotBCIB. Interpreting epidemiological research: blinded comparison of methods used to estimate the prevalences of inherited mutations in BRCA1. J Med Genet 2001;38:824-33

12 Couch FJ, DeShano ML, Blackwood MA, Calzone K, Stopfer J, Campeau L, Ganguly A, Rebbeck T, Weber BL. BRCA1 mutations in women attending clinics that evaluate the risk of breast cancer. N Engl J Med 1997;336:1409-15.

13 Shattuck-Eidens D, Oliphant A, McClure M, McBride C, Gupte J, Rubano T, Pruss D, Tavtigian SV, Teng DHF, Adey N, Staebell M, Gumpper K, Lundstrom R, Hulick M, Kelly M, Holmen J, Lingenfelter B, Manley S, Fujimura F, Luce M, Ward B, Cannon-Albright L, Steele L, Offit K, Gilewski T, Norton L, Brown K, Schulz C, Hampel H, Schluger A, Giulotto E, Zoli W Ravaioli A, Nevanlinna H, Pyrhonen S, Rowley P, Loader S, Osborne MP, Daly M, Tepler I, Weinstein PL, Scalia JL, Michaelson R, Scott RJ, Radice P, Pierotti MA, Garber JE, Isaacs C, Peshkin B, Lippman ME, Dosik MH, Caligo MA, Greenstein RM, Pilarski R, Weber BL, Burgemeister R, Frank TS, Skolnick MH, Thomas A. BRCAl sequence analysis in women at high risk for susceptibility mutations: risk factor analysis and implications for genetic testing. JAMA 1997;278:1242-50.

14 Berry D, Parmigiani G, Sanchez J, Schildkraut J, Winer EP. Probability of carrying a mutation of breast-ovarian cancer gene BRCA1 based on family history. J Natl Cancer Inst 1997;89:227-38

15 Benichou J. A computer program for estimating individualized probabilities of breast cancer. Comput Biomed Res 1993;26:373-82.

16 Benichou J, Gail MH, Mulvihill JJ. Graphs to estimate an individualized risk of breast cancer. J Clin Oncol 1996;14:103-10.

17 Gail MH, Brinton LA, Byar DP, Borle DK, Green SB, Schairer C, Mulvihill JJ. Projecting individualized probabilities of developing breast cancer for white females who are being examined annually. J Natl Cancer Inst 1989;81:1879-86.
18 Claus EB, Risch NR, Thompson WD. The calculation of breast cancer risk for women with a first degree family history of ovarian cancer. Breast Cancer Res Treat 1993;28:115-20.

19 Claus EB, Risch N, Thompson WD. Autosomal dominant inheritance of early onset breast cancer: implications for risk prediction. Cancer 1994;73:643-51.

20 McGuigan KA, Ganz PA, Breant C. Agreement between breast cancer risk estimation methods. J Natl Cancer Inst 1996;88:1315-17.

21 Armstrong K, Eisen A, Weber BL. Assessing the risk of breast cancer. N Engl J Med 2000;342:564-71.

22 Kerlikowske K, Brown JS, Grady DG. Should women with familial ovarian cancer undergo prophylactic oophorectomy? Obstet Gynecol 1992;80:700-7.

23 Struewing JP, Hartge $P$, Wacholder S, Baker SM, Berlin M, McAdams M, Timmerman MM, Brody LC, Tucker MA. The risk of cancer associated with specific mutations of BRCA1 and BRCA2 among Ashkenazi Jews. N Engl J Med 1997;336:1401-8.

24 King M-C, Group NYBCSC. Breast and ovarian cancer risks among women with BRCA1 and BRCA2 mutations in The New York Breast Cancer Study (NYBCS). Am J Hum Genet 2001;68:292.

25 Vasen HFA, Mecklin J-P, Meera Khan P, Lynch HT. The International Collaborative Group on Hereditary Non-Polyposis Colorectal Cancer (ICGHNPCC). Dis Colon Rectum 1991;34:424-5.

26 Vasen HFA, Watson P, Mecklin J-P, Lynch HT. New clinical criteria for hereditary nonpolyposis colorectal cancer (HNPCC, Lynch syndrome) proposed by the International Collaborative Group on HNPCC. Gastroenterology 1999;116:1453-6.

27 Salovaara $R$, Loukola A, Kristo $P$, Kaariainen $H$, Ahtola $H$, Eskelinen $M$, Harkonen N, Julkunen R, Kangas E, Ojala S, Tulikoura J, Valkamo E, Jarvinen H, Mecklin J-P, Aaltonen LA, de la Chapelle A. Population-based molecular detection of hereditary nonpolyposis colorectal cancer. J Clin Oncol 2000:18:2193-200.

28 Rodriguez-Bigas MA, Bolan CR, Hamilton SR, Henson DE, Jass JR, Meera Khan P, Lynch HT, Perucho M, Smyrk T, Sobin L, Srivastava S. A National Cancer Institute workshop on hereditary nonpolyposis colorectal cancer syndrome: meeting highlights and Bethesda guidelines. J Natl Cancer Inst 1997;89:1758-61

29 Syngal S, Fox EA, Eng C, Kolodner RD, Garber JE. Sensitivity and specificity of clinical criteria for hereditary nonpolyposis colorectal cancer-associated mutations in MSH2 and MLH1. J Med Genet 2000;37:641-5.

30 Association AG. American Gastroenterological Association medical position statement: hereditary colorectal cancer and genetic testing. Gastroenterology 2001;121:195-7

31 Aaltonen LA, Salovaara R, Kristo P, Canzian F, Hemmenki A, Peltomaki P Chadwick RB, Kaariainen H, Eskelinen M, Jarvinen $H$, Mecklin J-P, de la Chapelle A. Incidence of hereditary nonpolyposis colorectal cancer and the feasibility of molecular screening for the disease. N Engl J Med 1998;338: 1481-7.

32 St John DJ, McDermott FT, Hopper JL, Debney EA, Johnson WR, Hughes ES Cancer risk in relatives of patients with common colorectal cancer. Ann Intern Med 1993; 1 18:785-90.

33 Houlston RS, Murday V, Harocopos C, Williams CB, Slack J. Screening and genetic counseling for relatives of patients with colorectal cancer in a family cancer clinic. BMJ 1990;301:366-8.

34 Xu J, Meyers DA, Freije D, Isaacs SD, Wiley K, Nusskern DR, Ewing C, Wilkens E, Bujnovszky P, Bova GS, Walsh PC, Isaacs WB, Schleutker J, Matikainen M, Tammela T, Visakorpi T, Kallioniemi OP, Berry R, Schaid D, French A, McDonnell S, Schroeder J, Blute M, Thibodeau S, Trent JM. Evidence for a prostate cancer susceptibility locus on the $\mathrm{X}$ chromosome. Nat Genet 1998;20:175-9.

35 Berthon P, Valeri A, Cohen-Akenine A, Drelon E, Paiss T, Wohr G, Latil A, Millasseau P, Mellah I, Cohen N, Blanche H, Bellane-Chantelot C, Demenais F, Teillac $P$, Le Duc A, de Petriconi R, Hautmann R, Chumakov I, Bachner L, Maitland NJ, Lidereau R, Vogel W, Fournier G, Mangin P, Cussenot $O$. Predisposing gene for early onset prostate cancer, localized on chromosome 1q42.2-43. Am J Hum Genet 1998;62:1416-24.

36 Gibbs M, Stanfor JL, Mclndoe RA, Jarvik GP, Kolb S, Goode EL, Chakrabarti L, Schuster EF, Buckley VA, Miller EL, Brandzel S, Li S, Hood L, Ostrander EA Evidence for a rare prostate cancer susceptibility locus at chromosome $1 \mathrm{p} 36$. Am J Hum Genet 1999;64:776-87.

37 Smith JR, Freije D, Carpten JD, Gronberg H, Wu J, Isaacs SD, Brownstein MJ Bova GS, Guo H, Buinovszky P, Nusskern DR, Damber J-E, Bergh A. Emanuelsson M, Kallioniemi OP, Walker-Daniels J, Bailey-Wilson JE, Beaty TH, Meyers DA, Walsh PC, Collins FS, Trent JM, Isaacs WB. Major susceptibility locus for prostate cancer on chromosome 1 suggested by a genome-wide search. Science 1996;274:1371-4.

38 Carpten JD, Nupponen N, Isaacs S, Sood R, Robbins C, Xu J, Faruque M Moses T, Ewing C, Gillanders E, Hu P, Bujnovszky P, Makalowska I, Baffoe-Bonnie A, Faith D, Smith J, Stephan D, Wiley K, Brownstein MJ, Gildea D, Kelly B, Jenkins R, Hostetter G, Matikainen M, Schleutker J, Klinger K, Connors T, Xiang Y, Wang Z, De Marzo A, Papadopoulos N, Kallioniemi OP, Burk R, Meyers DA, Gronberg H, Meltzer P, Silverman R, Bailey-Wilson JE, Walsh PC, Isaacs WB, Trent JM. Germline mutations in the ribonuclease $\mathrm{L}$ gene in families showing linkage with $\mathrm{HPC1}$. Nat Genet 2002;30:181-4.

39 Tavtigian SV, Simard J, Labrie F, Skolnick MH, Neuhausen SL, Rommens J, Cannon-Albright LA. A strong candidate prostate cancer predisposition gene at chromosome 17p. Am J Hum Genet 2000;67S:7.

40 Rebbeck T, Walker AH, Zeigler-Johnson D, Weisburg S, Martin A-M, Nathanson KL, Wein AJ, Malkowicz SB. Association of HPC2/ELAC2 genotypes and prostate cancer. Am J Hum Genet 2000;67:1014-19. 
41 Woolf CM. An investigation of the familial aspects of carcinoma of the prostate. Cancer 1960;13:739-44.

42 Steinberg GD, Cater BS, Beaty TH, Childs B, Walsh PC. Family history and the risk of prostate cancer. Prostate 1990;17:337-47.

43 Spitz MR, Currier RD, Fueger JJ, Babaian RJ, Newell GR. Familial patterns of prostate cancer: a case-control analysis. J Urol 1991;146:1305-7.

44 Hayes RB, Liff JM, Pottern LM, Greenberg RS, Schoenberg JB, Schwartz AG, Swanson GM, Silverman DT, Brown LM, Hoover RN, Fraumeni JF. Prostate cancer risk in US blacks and whites with a family history of cancer. Int J Cancer 1995:60:361-4.

45 Kefford RF, Newton Bishop JA, Bergman W, Bergman W, Tucker MA, Consortium MG. Counseling and DNA testing for individuals perceived to be genetically predisposed to melanoma: a consensus statement of the Melanoma Genetics Consortium. J Clin Oncol 1999;17:3245-51.

46 Monzon J, Liu L, Brill H, Goldstein AM, Tucker MA, From L, McLaughlin J, Hogg D, Lassam NJ. CDKN2A mutations in multiple primary melanomas. N Engl J Med 1998;338:879-87.

47 Goldstein AM, Fraser MC, Struewing JP, Hussussian CJ, Ranade K, Zametkin DP, Fontaine LS, Organic SM, Dracopoli NC, Clark WH, Tucker MA. Increased risk of pancreatic cancer in melanoma-prone kindreds with p16 $6^{\text {INK4 }}$ mutations. N Engl J Med 1995;333:970-4.

48 Vasen HFA, Gruis NA, Frants RR, Van der Velden PA, Hille ETM, Bergman W. Risk of developing pancreatic cancer in families with familial atypical multiple mole melanoma associated with a specific 19 deletion of pl6 (p16-LEIDEN). Int J Cancer 2000;87:809-11

49 Ford D, Bliss MM, Swerdlow AJ, Armstrong BK, Franceschi S, Green A, Holly EA, Mack T, Mackie RM, Osterlind A. Risk of cutaneous melanoma associated with a family history of the disease: the International Melanoma Analysis Group (IMAGE). Int J Cancer 1995;62:377-81.

50 Birch JM, Hartley AL, Blair V, Kelsey AM, Harris M, Teare MD, Jones PH. Cancer in the families of children with soft tissue sarcoma. Cancer 1990;66:2239-48.

51 Garber JE, Goldstein AM, Kantor AF, Dreyfus MG, Fraumeni JF, Li FP. Followup study of twenty-four families with Li-Fraumeni syndrome. Cancer Res 1991;51:6094-7.

52 Li FP, Fraumeni JF, Mulvihill J, Blattner WA, Dreyfus MG, Tucker MA, Miller RW. A cancer family syndrome in twenty-four kindreds. Cancer Res 1988:51:6094-7.

53 Eeles RA. Predictive testing for germline mutations in the p53 gene: are all the questions answered? Eur J Cancer 1993;29A:1361-5.

54 Varley JM, McGown G, Thorncroft M, Santibanez-Koref MF, Kelsey AM Tricker KJ, Evans DG, Birch JM. Germ-line mutations of TP53 in Li-Fraumeni families: an extended study of 39 families. Cancer Res 1997;57:3245-52.

55 Birch JM, Hartley AL, Trickier KJ, Prosser J, Condie A, Kelsey AM, Harris M, Jones PH, Binchy A, Crowther D. Prevalence and diversity of constitutional mutations in the $\mathrm{p} 53$ gene among 21 Li-Fraumeni families. Cancer Res 1994;54:1298-304.

56 Carty SE, Helm AK, Amico JA, Clarke MR, Foley TP, Watson CG, Mulvihill JJ. The variable penetrance and spectrum of manifestations of multiple endocrine neoplasia type 1. Surgery 1998;124:1106-14.

57 Hodgson SV, Maher ER. Multiple endocrine neoplasia type 1. A practical guide to human cancer genetics, 2nd ed. Cambridge: Cambridge University Press, 1999:191-3.

58 Eng C, Mulligan LM, Smith DP, Healey CS, Frilling A, Rave F, Neumann HPH Pfragner R, Behmel A, Lorenzo MJ, Stonehouse TJ, Ponder MA, Ponder BAJ. Mutation of the RET protooncogene in sporadic medullary thyroid carcinoma. Genes Chromosomes Cancer 1995;12:209-12.

59 Goldgar DE, Easton DF, Cannon-Albright L, Skolnick MH. Systematic population-based assessment of cancer risk in first-degree relatives of cancer probands. J Natl Cancer Inst 1994;86:1600-7.

60 Ron E, Kleinerman RA, Bolce JD, LiVolsi VA, Flannery JT, Fraumeni JF. A population-based case-control study of thyroid cancer. J Natl Cancer Inst 1987;79:1-12

61 Varley JM, McGown G, Thorncroft M, James LA, Margison GP, Forster G, Evans DG, Harris M, Kelsey AM, Birch JM. Are there low-penetrance PT53 alleles? evidence from childhood adrenocortical tumors. Am J Hum Genet 1999;65:995-1006.

62 Wagner J, Portwine C, Rabin K, Leclerc J, Narod SA, Malkin D. High frequency of germline p53 mutations in childhood adrenocortical cancer. J Natl Cancer Inst 1994;86:1707-10.

63 Neumann HPH, Bausch B, McWhinney SR, Bender BU, Gimm O, Franke G Schipper J, Klisch J, Altehofer C, Zerres K, Januszewicz A, Eng C, Smith WM Munk R, Manz T, Glaesker S, Apel TW, Treier M. Reineke M, Walz MK, Hoang-Vu C, Brauckhoff M, Klein-Franke A, Klose P, Schmidt H, MaierWoelfle M, Peczkowska M, Szmigielski C, Eng C, Group F-W-CPS. Germ-line mutations in nonsyndromic pheochromocytoma. N Engl J Med 2002:346:1459-66.

64 Drovdlic CM, Myers EN, Peters JA, Baysal BE, Brackmann DE, Slattery WH, Rubinstein WS. Proportion of heritable paraganglioma cases and associated clinical characteristics. Laryngoscope 2001;111:1822-7.

65 Eng C. Will the real Cowden syndrome please stand up: revised diagnostic criteria. J Med Genet 2000;37:828-30.

66 Eng C, Hampel H, de la Chapelle A. Genetic testing for cancer predisposition. Annu Rev Med 2001;52:371-400.

67 Jarvinen H, Aarnio M, Mustonen H. Controlled 15-year trial on screening for colorectal cancer in families with hereditary nonpolyposis colorectal cancer. Gastroenterology 2000;1 18:829-34.

68 Sweet K, Bradley T, Westman JA. Recognition of high risk individuals for hereditary cancer syndromes and referral by comprehensive cancer center staff. Am J Hum Genet 2000;67S:1385. 